Please quote as: Ye, H.; Kanhanhalli, A.; Huber, M. J.; Bretschneider, U.; Blohm, I.; Goswami, S.; Leimeister, J. M. \& Krcmar, H. (2012): Collaboration and the Quality of User Generated Ideas in Online Innovation Communities. In: Proceedings of the Academy of Management 2012 Annual Meeting; 3. - 7. August 2012, Boston/Massachusetts, USA. 


\title{
Collaboration and the Quality of User Generated Ideas in Online Innovation Communities
}

\begin{abstract}
Enabled by Internet-based technologies, users are increasingly participating and collaborating in idea generation in online innovation communities. Beyond increasing the quantity of ideas contributed by users, firms are looking to obtain innovation ideas of better quality. However, with the limited understanding of the phenomenon, few studies have focused on investigating what determines the quality of collaboratively generated user ideas in online innovation communities. This study aims to address this knowledge gap by investigating the antecedents of the quality of user generated ideas from a knowledge collaboration perspective. Based on this perspective, we propose that idea creation effort, peer co-production, and peer feedback will directly and interactively influence the quality of user generated ideas. The model was tested with archival data from the SAPien's innovation community as well as idea quality rating data from experts. The results reveal that idea creation effort and peer feedback affect the quality of user generated idea. Further, idea creation effort negatively moderates the relationship between peer co-production and the quality of user generated ideas.
\end{abstract}

Keywords: User Generated Idea Quality, Knowledge Collaboration, SAPiens Innovation Community, Peer Co-production, Peer Feedback, Idea Creation Effort 


\section{INTRODUCTION}

Development of high quality ideas and successful innovations remains one of the essential challenges for companies (Soukhoroukova et al. 2012). In order to obtain a continuous stream of ideas, companies are increasingly including external users in the process of innovation (von Hippel 2005) with the help of Internet-based technologies such as social media tools (Kim and Miranda 2011). This is because users are considered to be able to generate valuable ideas concerning the improvement of existing products or services and the design of new products or services (Di Gangi et al. 2010; Poetz and Schreier 2009). One such mechanism by which users are being included in the process of idea generation for organizational innovations is through online innovation communities (Di Gangi et al. 2010; Kim and Miranda 2011). Examples of such platforms include Dell Ideastorm, where individual users contribute ideas to Dell's products and services, and My Starbucks Idea, where customers do the same for Starbucks.

Despite the importance of including users' inputs in idea generation for organizational innovations, firms find it difficult to obtain user generated ideas of good quality through online innovation communities (Roman 2009; Soukhoroukova et al. 2012), that is, where quality is often defined in terms of novelty, relevance, and thoroughness (Dean et al. 2006). Organizations may obtain more ideas - thought not necessarily better quality ones - by including users in the process of innovation ${ }^{1}$. Thus, firms want to know how users can be facilitated to generate ideas of quality through online innovation communities. Particularly, ideas are often generated through the collaboration of users (Girotra et al 2010). However, it is unclear how user collaboration impacts the quality of ideas in such communities.

\footnotetext{
${ }^{1}$ http://www.economist.com/node/21542154
} 
Previous research on idea generation has suggested that collaborative teams can generate more and better ideas than do the same number of single individuals generating ideas in isolation (Girotra et al. 2010; Singh and Fleming 2010; Taylor and Greve 2006). Specifically, in examining the influence of collaboration on the variance of idea quality in the context of patents, Singh and Fleming (2010) reveal that collaboration reduces the number of bad ideas and increases the number of high quality ideas. This result agrees with the analytical findings of Kavadias and Sommer (2009). Furthermore, experimental studies indicate that collaborative teams can improve the quality of ideas generated (e.g., Girotra et al. 2010). However, it is unclear how collaboration can help improve the quality of ideas generated.

Besides, past organizational studies have identified the problems of collaboration which may result in poor performance (e.g., Diehl and Stroebe 1987; Kavadias and Sommer 2009; Paulus and Brown 2003). Some of these problems, e.g., idea blocking (only one person can typically speak at a given time, and thus ideas might be forgotten while listening to and understanding the speaker) and interpersonal tensions (e.g., members may not criticize the idea in the presence of idea generators), may be more salient for offline than online collaboration. This is because, in online settings, such as Wikipedia, individuals can freely propose and revise content at any time without necessarily considering the presence of other content generators (Ransbotham et al. forthcoming). Further, their contributions are recorded and stored, making it easy for community users to retrieve the postings or comments. However, other problems of collaboration such as free-riding may be exacerbated in online settings (Wasko and Faraj 2005). Such contextual differences require further investigation of collaborative idea generation in online communities.

Previous literature in the online context has mainly focused on examining user generated content in Wikipedia. Studies have found that collaboration among content contributors and direct effort 
of contributors affects the collaborative outcomes (e.g., Ransbotham et al. forthcoming; Ransbotham and Kane 2011). For example, Ransbotham et al. (forthcoming) observed that direct efforts of contributors affect the quality of articles in Wikipedia in terms of a proxy measure i.e., viewership. However, there is a lack of understanding of how collaboration among users determines the quality of user generated ideas in online innovation communities and particularly for direct measures of quality ratings.

Motivated thus, this paper aims to fill this knowledge gap by developing a model to address the research question: How does knowledge collaboration determine the quality of user generated ideas in online innovation communities? Drawing on related literature in online communities, this paper proposes that knowledge collaboration among users will lead them to generate ideas of better quality. Specifically, we propose that in the context of user generated ideas in online innovation communities, three dimensions of knowledge collaboration, i.e., idea creation effort, peer co-production, and peer feedback, will directly and interactively affect the quality of user generated ideas. We tested our model in the SAPiens' innovation community, which is used to collect ideas from users about how to improve SAP software (Blohm et al. 2011). Since SAPiens is a well-known community where users collaboratively generate innovation ideas, this fits well with the scope of our study. The findings of this paper are expected to contribute to research and practice in online innovation communities and collaborative idea generation.

\section{CONCEPTUAL BACKGROUND}

This section reviews the relevant concepts and literature on idea quality, idea generation, and online knowledge collaboration. These concepts form the basis for our research model. 
Submission \#16803

\section{Idea Quality}

Idea quality is a complex construct and includes different dimensions (Dean et al. 2006). Previous creativity literature suggests that quality ideas are generally characterized as being new and useful (Amabile 1996; Plucker et al. 2004). Novelty or newness is defined as something being unique, unobvious, or rare (e.g., Dean et al. 2006). In the context of innovation, novelty refers to the extent that the idea has not been expressed before (Magnusson et al. 2003). In this study, idea raters examine how unique the idea is or how uncommon it is in the overall population of ideas when judging its novelty.

However, an idea's novelty is not sufficient for being useful. Usefulness is the extent to which the idea responds to, or solves, a problem that is tangible and vital (Amabile 1996; Dean et al. 2006). This dimension is also labeled as an idea's value or relevance (Dean et al. 2006; Kristensson et al. 2004). An idea is relevant if it satisfies the goals framed by the problem setter (Dean et al. 2006). In the context of new product development, this refers frequently to an idea's financial potential (Lilien et al. 2002), the strategic importance in terms of enabling competitive advantage (Cady and Valentine 1999; Lilien et al. 2002), as well as the customer benefit that an idea endows (Piller and Walcher 2006).

In addition to novelty and relevance, through a thorough review, Dean et al. (2006) identified two other dimensions of quality ideas used in previous literature, i.e., elaboration (specificity), and workability. Thus, another trait of a high quality idea is its elaboration ${ }^{2}$, which can be seen as the extent that it is complete, detailed, and well understandable (Dean et al. 2006). This refers not only to an idea's description but also to its maturity (Lilien et al. 2002; MacCrimmon and

\footnotetext{
${ }^{2}$ Some studies have termed it as thoroughness (e.g., MacCrimmon and Wagner 1994).
} 
Submission \#16803

Wagner 1994). In the context of innovation ideas, elaboration refers to the extent to which the idea is complete and has an elaborative description (Blohm et al. 2011). Ideas that are vague or contain unclear causality are less useful than ideas that are more specific in these areas (MacCrimmon and Wagner 1994).

Last, idea workability refers to the extent to which the idea is acceptable and implementable (Dean et al. 2006). This concept is accounted variously in previous studies. For example, Cady and Valentine (1999) define quality as, among other things, the degree to which an idea can be successfully adopted by an organization, where adoption incorporates the generation, development, and implementation of the new idea.

\section{Idea Generation}

Idea generation has long been recognized as an important phase in the new product/service development process since it determines the success and costs of innovation (Bjork and Magnusson 2009; Reid and de Brentani 2004). It has become more salient in the context of globalization (Bjork and Magnusson 2009), when firms are facing increasing competition from around the world. This is also motivated by rapidly changing customer preferences and short product or service life cycles. Thus, organizations need to continuously innovate to ensure longterm competitiveness by obtaining a continuous stream of new ideas.

The success of idea generation for innovation typically depends on the quality of ideas identified (Girotra et al. 2010). In order to understand what kind of organizational structure is good for employees to generate high quality ideas, previous research has examined the effectiveness of idea generation by teams compared to that by the same number of individuals generating ideas in isolation (e.g., Singh and Fleming 2010; Girotra et al. 2010; Kavadias and Sommer 2009). Mixed 
results have been found about whether teams are more effective in generating a higher number of and better ideas than are individuals. Some studies have found that working in teams leads to multiple creative stimuli and interaction among participants, resulting in a highly effective idea generation process (e.g., Osborne 1957; Girotra et al. 2010; Singh and Fleming 2010). These studies suggest that idea generation should be conducted by teams, e.g., team brainstorming.

Other studies have found that the number of ideas generated is significantly higher when individuals work by themselves and the average quality of ideas is not different between individuals and team processes (e.g., Diehl and Strobe 1987; Ulrich and Eppinger 2007). They argue that why idea generation by teams is less effective than by individuals can be attributed to two main reasons (Diehl and Strobe 1987; Gallupe et al. 1991), i.e., idea blocking (only one person can speak at a given time, and consequently ideas might be forgotten while listening to and understanding the speaker) and interpersonal tensions (members may not criticize the idea in the presence of idea generators). Accordingly, these studies suggest that idea generation for innovation should include significant effort by individuals working independently of one another. Therefore, it is not clear whether individuals or team collaboration may produce better ideas, particularly in new online contexts such as individuals collaborating to generate ideas in online innovation communities.

With the emergence of Internet-based technologies, companies are increasingly including customers in the process of innovation (von Hippel 2005). Several large companies, such as Starbucks and Dell, have undertaken such initiatives for idea generation. They have opened up this stage of innovation to their customers, inviting anyone to raise new ideas for possible products or services or their improvement through online innovation communities (Di Gangi et al. 2010; Kim and Miranda 2011). These initiatives have been shown to be successful in past 
studies (e.g., Di Gangi et al. 2010). Particularly, previous research has found that customers or users can generate valuable ideas in offline (e.g., Poetz and Schreier 2009) as well as online settings (e.g., Soukhoroukova et al. 2012). For example, through analyzing the performance of idea market, Soukhoroukova et al. (2012) show that organizations can obtain a stream of ideas for innovation generated by users. However, there is limited understanding and a lack of studies that investigate the influence of collaboration on the quality of user generated ideas (through direct measures of quality) in the context of online innovation communities.

In the context of online innovation communities, individuals can freely propose and revise ideas at any time without taking into consideration the presence of other idea generators (Blohm et al. 2011). In some communities, postings could be anonymous such that users do not know who the idea generator is. Contributions/postings/dialogs are also usually stored in discussion threads, making it easy to check through the history of dialogs in these communities. Therefore, the challenges of offline collaboration for idea generation (i.e., idea blocking and interpersonal tensions) may not be as salient in the context of online innovation communities. However, other problems of collaboration, e.g., free-riding, may be exacerbated in online communities (Wasko and Faraj 2005). Such contextual differences may result in variations regarding how collaboration will affect the quality of ideas generated in online communities as compared to offline settings. Therefore, the quality of user generated ideas through collaboration in online innovation communities requires further investigation.

\section{Online Knowledge Collaboration}

In the context of online communities, knowledge collaboration is defined as individual acts of offering knowledge to others as well as adding to, recombining, modifying, and integrating 
knowledge that others have contributed (Faraj et al. 2011). Online knowledge collaboration can take various forms. It could involve an individual posting a question or idea to an online community and then engaging in a process of reflecting on incoming responses and posting clarifying questions or ideas (Wasko and Faraj 2005; Cummings et al. 2002). It could also involve parties engaging in adding to, recombining, modifying, and integrating knowledge that others have contributed (Jarvenpaa and Majchrzak 2010). Yet another form involves providing feedback on the knowledge contributed, while still waiting for others to include the feedback in the knowledge (Faraj et al. 2011).

Past literature suggests that online knowledge collaboration will help generate better content in the community (e.g., Ransbotham and Kane 2011; Ransbotham et al. forthcoming). For example, in a study of collaborative content generation in Wikipedia, Ransbotham and Kane (2011) report that collaboration of new and experienced members affects the success of knowledge creation in terms of the articles being featured (best articles) in Wikipedia. However, how specific aspects of knowledge collaboration in online innovation communities may influence the quality of ideas has not been theorized and tested.

This paper models and empirically tests the impact of three aspects of knowledge collaboration among individuals on the quality of user generated ideas. First, the knowledge efforts provided by users are the primary inputs for developing user-generated ideas. For user generated content, the direct effort input by content contributors, in terms of the number of edits to the content and the length of the content, is found to be an important predictor of the quality of user generated content (Ransbotham and Kane 2011). In the context of our study, the idea creation effort by the idea author should be a salient predictor of the quality of user generated ideas. Second, other users also contribute to the idea by revising the idea or providing a different perspective on it. 
Therefore, peer co-production by other users may also be an important predictor of the quality of user generated ideas. Third, the feedback from other users could serve as a direction or guideline for the idea author himself or herself to improve the idea. Therefore, peer feedback could also be an antecedent of the quality of user generated ideas. We thus investigate whether idea creation effort, peer co-production, and peer feedback will affect the quality of user generated ideas in online innovation communities.

\section{RESEARCH MODEL AND HYPOTHESES}

Based on the idea quality, idea generation, and online knowledge collaboration literatures, we propose a research model to explain the quality of user generated ideas in online innovation communities. We expect that three aspects of knowledge collaboration will directly and interactively affect the quality of user generated ideas. Specifically, we hypothesize that idea creation effort, peer coproduction, and peer feedback will positively affect the quality of user generated ideas. Additionally, we expect that idea creation effort will moderate the relationship between peer coproduction and the quality of user generated ideas as well as the relationship between peer feedback and the quality of user generated ideas. The proposed model is shown in Figure 1.

Insert Figure 1 about here

\section{Idea Creation Effort}

Idea creation effort refers to the time and effort input by idea creators in constructing, developing, and codifying the ideas (Jonson 2005). Idea creation is directly associated with creativity and 
creative processes. It includes sourcing of ideas as well as the processes that underlie their formation (Tschang and Szczypula 2006). Through idea sourcing, individuals will go through the process of searching for possible combinations or recombinations of information (Singh and Fleming 2010). This may include combinatorial thought trials among other mechanisms.

Past creativity literature suggests that the ability to generate novel ideas is based on the availability of knowledge, which can be shaped by individuals' search effort (e.g., Lyles and Schwenk 1992; Taylor and Greve 2006). A broader search results in more idea variety and can identify ways to combine knowledge that challenges the beliefs that constrain innovative behavior (Taylor and Greve 2006). The effort put into the search and the diversity of information search determines the size of recombinant opportunities (Kornish and Ulrich 2011), all of which will affect the quality of ideas generated (Singh and Fleming 2010). Further, the idea author needs to compose the idea into language or words and communicate it to others (Kavadias and Sommer 2009). The more time and effort put into clarifying the idea will help others to better evaluate its quality (Diehl and Stroebe 1987).

Past creativity literature also suggests that creativity requires application of deep knowledge because individuals must understand a knowledge domain to push its boundaries with any nontrivial likelihood of success (Sternberg and O' Hara 2000). In the context of our study, idea creators may need to put in much time and effort to explore the knowledge domain and try to push its boundaries. Thus, idea creation effort should affect the quality of ideas generated.

This is also consistent with previous user generated content literature, which has found that the contribution effort by users will directly affect the value of user generated content (e.g., Ransbotham et al. forthcoming; Foutz and Jank 2010). This is because more input by content 
creators will help improve the quality of content not only by clarifying the content with a language that can be commonly understood but also by searching for more information. In the context of our paper, following the logic discussed above, the effort input by idea authors, such as search, combination, and idea codification effort, should directly affect the quality of user generated ideas. Therefore, we hypothesize:

\section{H1: Idea creation effort is positively related to the quality of the user generated idea}

\section{Peer Co-production}

The creativity literature frames innovative ideas as arising from diverse knowledge, processes that allow for creativity, and tasks directed toward creative solutions (Gilson and Shalley 2004). Diverse knowledge provides more components useful for making innovative combinations, which gives the opportunity for significant advances (Fleming 2001). A high number of collaborators is an important source of diverse knowledge (Taylor and Greve 2006; Ransbotham et al. forthcoming). Individuals have different cognitive strategies and experiences, leading to variation in knowledge and problem solving approaches that can help identify, and use, multiple knowledge components (Taylor and Greve 2006). Thus, collaboratively working with peers exposes individuals to a broader set of perspectives, and cross-fertilization of ideas results in more creative outcomes (Taylor and Greve 2006).

Peer co-production in the online context refers to peers' participating in revising, developing, and clarifying the idea with the support of technologies such as wikis. According to the logic discussed above, the greater the number of collaborators participating in idea coproduction, the better the ideas generated. Thus, enabled by technologies such as wikis, peers can contribute a unique set of diverse knowledge to the innovative idea. The diverse perspective and knowledge 
allows peers as well as idea creators to have more options for combination and hence improve the quality of ideas. Additionally, more revisions by others can include insights from different perspectives. This will also improve the opportunity space of ideas by including different elements inside it (Kornish and Ulrich 2011).

Past literature in value co-creation suggests that peers are able to co-create the value of innovations (Prahalad and Ramaswamy 2004; Sawhney et al. 2005). In the context of our paper, peers can participate in revising and clarifying others' ideas, hence contributing to the quality of the ideas. Similar arguments have been suggested in past literature on open source software (e.g., Feller et al. 2008; Lakhani and von Hippel 2003). For example, Lakhani and von Hippel (2003) proposed that peer developers can collectively develop better software. Following the same logic, we hypothesize:

\section{H2: Peer coproduction is positively related to the quality of the user generated idea}

As discussed above, we expect that there is an interaction between peer coproduction and idea creation effort. As more creation effort is put in and the idea becomes more mature, it is difficult for peers to contribute towards better quality idea. For example, Ransbotham et al. (forthcoming) purport that, as the user generated content becomes mature, others find it difficult to contribute to the content. When the components of the idea become saturated with much effort put into creating them, the contribution of peers is less influential to improve the quality of the idea. Therefore, we propose:

H3: When idea creation effort is high, the relationship between peer coproduction and the quality of the user generated idea will be weakened 
Submission \#16803

\section{Peer Feedback}

Peer feedback in the online context refers to peers' comments and suggestions posted regarding the idea enabled by Internet based technologies, such as wikis. On the one hand, it points out the necessity for further improvement. Such information provided by peers could help the idea creators and others to edit the idea and improve it accordingly (Dominick et al. 1997). Improvement information could include further elaboration of the idea using examples, or describing the idea with simpler language. On the other hand, peer feedback may serve as a clue for idea creators to reflect on the idea and their own capabilities. By learning from peer feedback, creators start to think about the drawbacks of the idea and exert more effort on resolving these to improve the idea (Perry-Smith and Shally 2003).

In past educational learning literature, feedback has been found to provide students with information that either confirms what they know or changes their existing knowledge and beliefs (Mory 2004). Nicol and Macfarlane-Dick (2006) suggest that feedback serves as a form of formative assessment, designed to improve and accelerate learning. In the context of our paper, following this logic, peer feedback could be an opportunity for the idea author and peers to learn and improve on the idea.

Similar arguments have been found in the past innovation literature, where feedback from external experts and non-experts is seen to be important for organizations to develop novel combinations of knowledge (e.g., Hargadon and Sutton 1997). For example, in their study of new product development, Hargadon and Sutton (1997) note that the product development firm IDEO invited designers not associated with a focal project to provide feedback and advice in the initial design stages. In this way, IDEO attempted to facilitate the combination of different 
Submission \#16803

knowledge domains to generate creative product designs. Similarly, in the context of our study, we expect that peer feedback will serve as a source of diverse knowledge, and facilitate novel combinations of knowledge to generate ideas of quality. Thus, we expect:

H4: Peer feedback is positively related to the quality of the user generated idea

The comments and suggestions from peers may inspire idea proposers to further improve the ideas. However, peers' comments will be less likely to enhance the idea if it is more mature. As content matures with more effort put into its creation, the idea will reach a stable equilibrium as it is refined through the ongoing work of its contributors, making it less adaptive to changes in the underlying knowledge. This is particularly acute in online settings where the collaborative platform can preserve and synthesize the contributions of prior members. Hence, we expect:

H5: When idea creation effort is high, the relationship between peer feedback and the quality of the user generated idea will be weakened

Apart from the independent variables discussed above, there could be other variables that may affect the quality of ideas generated. Such factors include idea duration, idea voting, and the experience of idea creators (Ransbotham et al. forthcoming; Ransbotham and Kane 2011). We include these as control variables in our model.

\section{RESEARCH METHODOLOGY}

\section{Research Context- SAPiens Community}

We conducted our research in "SAPiens" (www.sapiens.info), an online innovation community initiated and operated by the ERP software producer SAP. The SAPiens community is suitable for our study for several reasons. First, it invites users to contribute ideas on the improvement of 
SAP software. Second, users collaborate with each other to generate and revise ideas. Overall, it is considered as a successful community with broad-based participation. Thus, the SAPiens community fits well with the scope of our study.

SAPiens was launched in spring 2009, targeting users of SAP software. SAP users are invited to submit ideas that improve the SAP solution or bring about radical innovation in the scope of the SAP product. Ideas have to be submitted via an Internet toolkit designed and implemented especially for the SAPiens community and can be visited only after registration. Each submitted idea is visualized in an idea pool, a separate section of the online platform. By March 2011 more than 320 SAP users had become members of the SAPiens community. Of those users, 233 actively participated by submitting at least one idea. The rest participated in scoring and commenting on the submissions of other users or simply reading through them. The comments and user evaluations can help the ideas authors to refine their ideas.

\section{Operationalization}

We adopted the measurements for the constructs in our model from past literature (see Table 1). For idea creation effort, we formatively measured it with the number of revisions made by the idea author to the idea and the idea length. The more revisions, the more time and effort the idea author has spent on idea creation (Ransbothams and Kane 2011). The longer the length of the idea, the more time and effort the idea author has spent on constructing and codifying the idea (Yang et al. 2009). Thus, the two items formatively constitute the latent variable, i.e., idea creation effort. We measured peer co-production with the number of edits made by peers and the number of peers participating in editing and developing the idea. This is because the two items can reflect the degree of collaboration with peers on the idea (Ransbotham et al. forthcoming). 
We measured peer feedback with the number of comments received. It is argued that as long as peers comment, they acknowledge the value of the idea and provide value by improving it (Ransbotham et al. forthcoming). Therefore, comments can reflect the peers' reaction to an idea which we expect to improve the idea.

Insert Table1 about here

For the dependent variable i.e., quality of user generated idea, we drew on the creativity literature for its measures. As described in the conceptual background section, we measure the quality of user generated ideas in terms of three dimensions, i.e., novelty, relevance, and elaboration. Workability is omitted from our measure since it is considered infeasible to gauge due to requirement of detailed implementation information. Following previous creativity research, we adopted the Consensual Assessment Technique (CAT) (Amabile 1996) to assess the quality of user generated ideas, a technique which has been commonly used to evaluate user generated ideas in product innovation (e.g., Blohm et al. 2011; Magnusson et al. 2003; Matthing et al. 2006). Therefore, we obtained data for the three dimensions of idea quality in an aggregated level. We measure the quality of user generated idea as a formative construct based on the three dimensions.

For the control variables, we directly collected the time elapsed (i.e., month elapsed) since the idea had been published as idea duration, the number of idea assessments (i.e., likes) that the idea has obtained as voting, and the number of ideas created or participated in coproduction as experience of the idea creator. 


\section{Data Collection}

We used a combination of data from expert ratings and archival data from the SAPiens community. For independent variables and control variables, we directly collected data from the SAPiens' database. The archival data was collected during a challenge that resulted in a sample of 86 ideas.

Through the CAT method, the ideas were evaluated by a jury consisting of experts in the domain of SAP. We contacted employees of SAP and the German SAP University Competence Centers, of which 11 agreed to be jury members. For evaluation, each idea description was pasted into separate evaluation forms, which also contained the scales for idea evaluation. Evaluation forms were handed out to each referee in a randomized order. Each member of the jury evaluated the ideas independently of the others. Each judge was asked to rate the quality of the user generated idea according to its novelty, elaboration, and relevance on a scale ranging from 1 (lowest) to 5 (highest). The value for each dimension of the quality of each user generated idea was calculated by averaging the scores from the judges.

\section{DATA ANALYSIS}

We analyzed the data by constructing a structural equation model using the Partial Least Square (PLS) algorithm. PLS is a suitable choice for analyzing the hierarchical model with formative constructs (i.e., idea creation effort and the quality of user generated idea) and moderating effects (i.e., H3 and H5) (Kim et al. 2010; Wetzels et al. 2009). Interaction terms were computed by cross-multiplying the standardized items of the relevant constructs (Chin et al. 2003). We used SmartPLS 2.0 software to conduct the analysis. We first tested for the measurement validity of the instrument, followed by hypothesis testing. The single item constructs (i.e., peer feedback, 
idea duration, creators' experience, and voting) were not tested. Idea creation effort and the quality of user generated idea were tested as formative constructs.

\section{Measurement Validity}

To validate our measurement model, convergent and discriminant validity of the reflective construct (i.e., peer co-production) was assessed (Hair et al. 2006). We tested for convergent validity by examining Cronbach's $\alpha(\mathrm{CA})(>0.7)$, composite reliability $(>0.7)$, average extracted variance (AVE) ( $>0.5$ ) (Straub et al. 2004; Fornell and Larcker 1981). Since there is only one reflective construct, i.e., peer co-production, we did not conduct factor analysis. Table 2 shows that the $\mathrm{CA}, \mathrm{CR}$ and $\mathrm{AVE}$ for peer co-production are satisfactory.

Since the quality of the user generated ideas was rated by experts, we checked the inter-rater reliability of the judgments by calculating Intra-class Correlation Coefficients (ICC) as recommended in the CAT (Amabile 1996). According to Amabile (1996), ICC coefficients should not be lower than 0.5 to ensure a sufficient inter-rater reliability. In our case, all ICCs are higher than 0.5 , suggesting a satisfactory inter-rater reliability (see Table 3 ).

Insert Tables $2 \& 3$ about here

For the formative constructs, i.e., idea creation effort and the quality of user generated content, we examined the weights and significance level (Chin et al. 2003). As shown in Table 4, the two dimensions of idea creation effort are significant and contribute to the construct. However, for the quality of user generated idea, mainly elaboration significantly contributes to the construct. 
Further, we examined the correlation table for all constructs. Table 5 provides evidence that the correlations between constructs are lower than 0.6 and thus there is no indication of multicollinearity. Further, since we collected data for the independent variables and dependent variable from two independent sources, common method variance should not influence the results (Podsakoff et al. 2003).

\section{Results of Hypothesis Testing}

We used SmartPLS to test the hypotheses by bootstrapping method. The path coefficients and explained variances for the structural model are shown in Table 6 . The model explains $37 \%$ of the variance of the quality of the user generated idea $\left(\mathrm{R}^{2}=0.37\right)$. All control variables (i.e., voting, idea duration, and creator's experience) are not found to affect the quality of the user generated idea.

Insert Table 6 about here

As is shown in Table 6, idea creation effort and peer feedback are positively related to the quality of the user generated idea (H1 and $\mathrm{H} 4$ supported). Idea creation effort negatively moderates the relationship between peer coproduction and the quality of user generated idea (H3 supported). Contrary to our prediction, peer coproduction is found to have no impact on the quality of the 
user generated ideas, and idea creation effort does not interact with peer feedback to influence the quality of user generated ideas (H2 and $\mathrm{H} 5$ not supported).

\section{DISCUSSION AND IMPLICATIONS}

The data by and large provides support for our model to explain the antecedents of quality of the user generated idea. The results of hypothesis testing show that idea creation effort and peer feedback affect the quality of the user generated ideas. Also, idea creation effort negatively moderates the relationship between peer co-production and quality of the user generated ideas.

Contrary to our hypothesis, peer coproduction has no effect on the quality of user generated ideas and idea creation effort does not moderate the relationship between peer feedback and quality of user generated ideas. This could be due to the reason that too many elements for ideas can distract the original ideas, leading to a different direction and obscure the boundary of the original idea (Singh and Fleming 2010). Too many inputs from different collaborations may also introduce conflicting arguments for the idea and hence decrease the quality of the original ideas (Singh and Fleming 2010). This negative effect is likely to curtail the positive effect of collaboration on idea quality.

\section{Theoretical Contribution}

This paper contributes to theory in the following ways. First, it adds to the creativity literature by examining the influence of online knowledge collaboration on the quality of user generated ideas. Specifically, we empirically test the influence of three aspects of online knowledge contribution i.e., idea creation effort, peer co-production, and peer feedback, on the quality of user generated ideas. It extends the past literature (e.g., Girotra et al. 2010; Singh and Fleming 2010) by 
showing that idea creation effort and peer feedback are important to the quality of user generated idea in the context of idea generation in online innovation communities. The study also indicates that peer coproduction has a moderated impact on the quality of user generated ideas.

Second, this paper contributes to user generated content literature by directly measuring the quality of user generated ideas. Previous studies have tended to use proxies of quality such as the status of the featured article (e.g., Ransbotham and Kane 2011) or viewership (e.g., Ransbotham et al. forthcoming). Our paper suggests an expert rated multi-dimensional operationalization of idea quality. Therefore, our study extends the previous literature by directly measuring the outcome of collaborations i.e., idea quality.

Third, this research contributes to the online knowledge collaboration literature. For example, Faraj et al. (2011) conceptually propose that the fluidity of online communities and collaboration between members helps generate good ideas. Our paper extends this literature by empirically measuring online knowledge collaboration and its impacts on the quality of user generated ideas in the context of online innovation communities. It also adds value to the existing literature on online knowledge collaboration by investigating the three aspects of knowledge collaboration (peer coproduction, peer feedback, and idea creation effort) and their interactions in online innovation communities.

\section{Limitations and Future Research}

The contributions of the paper should be interpreted in the face of its limitations. First, only one dimension significantly contributes to the quality of the user generated idea. This could be due to correlations in the judges' evaluations of the three dimensions. Future research could consider ways of decoupling the measures of the three dimensions. Second, we found that peer 
coproduction does not directly affect idea quality. This could be an interesting and important direction for future studies to explore under what conditions peer coproduction would have an impact on the quality of user generated ideas. Third, it could be interesting and worthwhile to investigate the quality of user generated ideas using other theoretical perspectives. Possible theoretical lenses could include social influence theory (Deutsch and Gerard 1995) or a community learning perspective (Wang and Ramiller 2009).

\section{Practical Implications}

Apart from the theoretical contributions, the paper also contributes to practice. First, it suggests the importance of including external users to contribute to innovative idea generation. External users or customers should be encouraged to participate in contributing their unique ideas to the idea generation process. Second, encouraging others to comment on existing ideas is an effective way to improve generated ideas. External users may be encouraged to provide feedback to current ideas, such as whether the idea is useful, or whether it needs revision. The feedback could be very important for idea creators to put in their own effort to improve the idea. Third, it could be important to control the conflicts between idea authors and other users in revising the idea. A monitor would be needed to solve the conflict, or a conflict solving mechanism should be established, such as voting for changes.

\section{CONCLUSION}

Despite firms' increasing recognition of the importance of collaboration in idea generation, there is a lack of understanding of how the collaboration among users in online innovation communities will affect the quality of user generated ideas. Considering the importance of the quality of new ideas to the success of innovation, practitioners have expressed substantial 
concerns on how the quality of user generated ideas can be improved (Soukhoroukova et al. 2012). To this end, this study developed a theoretical model based on the online knowledge collaboration perspective to explain what determines the quality of user generated ideas in online innovation communities. Our findings indicate that idea creation effort and peer feedback, positively affect the quality of user generated ideas, and that idea creation effort negatively moderates the relationship between peer coproduction and the quality of user generated ideas. Overall, this study should be useful for understanding collaborative idea generation in online innovation communities and the corresponding strategies to obtain high quality ideas.

\section{References}

Amabile, T. M. (1996). Creativity in context: Upate to Social Psychology of Creativity, Westview Press, Oxford.

Bjork, J., M. Magnusson. (2009). Where do good innovation ideas come from? Exploring the influence of network connectivity on innovation idea quality, Journal of Product Innovation Management, 26 (6), 662-670.

Blohm, I., Bretschneider, U., Leimeister, J. M., Krcmar, H. (2011). Does collaboration among participants lead to better ideas in IT-based idea competitions: An empirical investigation, International Journal of Networking and Virtual Organizations, 9 (2), 106-122.

Cady, S.H., Valentine, J. (1999). Team innovation and perceptions of consideration. What difference does diversity make? Small Group Research, 30(6), 730-750.

Chin, W.W., Marcolin, B.L., Newsted, P.R. (2003). A partial least squares latent variable modeling approach for measuring interaction effects: results from a Monte Carlo 
simulation study and an electronic-mail emotion/adoption study, Information Systems Research 14(2) 189-217.

Cummings, J.N., B. Butler, R. Kraut (2002). The Quality of Online Social Relationships, Communications of the ACM 45(7) 103-108.

Dean, D. L., J. M. Hender, J. L. Rodgers, E. L. Santanen (2006). Identifying Quality, Novel, and Creative Ideas: Constructs and Scales for Idea Evaluation. Journal of the Association for Information Systems 7(10), 646-699.

Deutsch, M., and Gerard, H.B. 1995, "A study of normative and information social influences upon individual judgment," Journal of Abnormal and Social Psychology 51(3) 629-636.

Di Gangi, P. M., Wasko, M. M., Hooker, R. E. 2010. Getting customers' idea to work for you: learning from Dell how to succeed with online user innovation communities, MIS Quarterly Executive, 9(4) 213-228.

Diehl, M., W. Stroebe. (1987). Productivity loss in brainstorming groups: Toward the solution of a riddle, Journal of Personality and Social Psychology, 53, 497-509.

Dominick, P. G., Reilly, R. R., \& McGourty, J. W. (1997). The effects of peer feedback on team member behavior. Group \& Organizational Management, 22(4), 508-520.

Faraj, S., Jarvenpaa, S. L., Majchrzak, A. (2011). Knowledge collaboration in online communities, Organization Science, 22(5), 1224-1239.

Feller, J., Finnegan, P., Fitzgerald, B., Hayes, J. (2008). From Peer Production to Productization: A Study of Socially Enabled Business Exchanges in Open Source Service Networks, Information Systems Research, 19(4), 475-493.

Fleming, L. (2001). Recombinant uncertainty in technological search, Management Science, 47 (1), 117-132. 
Fornell, N., Larcker, D.F. 1981. Evaluating structural equation models with unobservable variables and measurement error, Journal of Marketing Research, 18(1) 39-50.

Fouzt, N. Z., W. Jank. (2010). Prerelease demand forecasting for motion pictures using functional shape analysis of virtual stock markets, Marketing Science, 29(3), 568-579.

Gilson, L. L., Shalley, C. E. (2004). A little creativity goes a long way: An examination of teams; engagement in creative processes, Journal of Management, 30, 452-470.

Girotra, K., Terwiesch, K.T. Ulrich. (2010). Idea generation and the quality of the best idea, Management Science, 56(4), 591-605.

Gallupe, R. B., L. M. Bastianutti, W. H. Cooper. (1991). Unblocking brainstorms, Journal of Appied Psychology, 76(1), 137-142.

Hair, J. F, Black, W. C, Babin, B. J., Anderson, R. E., Tatham, R. L. 2006. Multivariate data analysis, (Six Edition). New Jersey: Pearson Education, Inc.

Hargadon, A., Sutton, R. (1997) Technology brokering and innovation in a product-development firm, Administrative Science Quarterly, 42, 716-749.

Jarvenpaa, S. L., Majchrzak, A. (2010). Vigilant interaction in knowledge collaboration: Challenges of online user participation under ambivalence, Information Systems Research, 21(4), 773-784.

Jonson, B. (2005). Design Ideation: the conceptual sketch in the digital age. Design Studies, 26(6), 613-624.

Kavadias, S., S. C. Sommer. (2009). The effects of problem structure and team expertise on brainstorming effectiveness, Management Science, 55(12), 1899-1913. 
Kim, S. W., Miranda S. M. (2011). A Call to Arms: A Social Movments Perspective in 'Issue' Surfacing on Social Media, Academy of Management Best Paper Proceedings, San Antonio, TX.

Kim, G., Shin, B., and Grover, V. 2010. "Investigating Two Contradictory Views of Formative Measurement in Information Systems Research," MIS Quarterly, 34(2) 345-365.

Kornish, L. J., Ulrich, K. T. (2011). Opportunity spaces in innovation: Empirical analysis of large samples of ideas, Management Science, 57(1), 107-128.

Kristensson, P., Gustafsson, A., Archer, T. (2004) Harnessing the creative potential among users, Journal of Product Innovation Management, 21(1), 4-14.

Lakhani, K., von Hippel, E. (2003). How open source software works: "free" user-to-user assistance, Research Policy, 32 (6), 923-943.

Lilien, G.L., Morrison, P.D., Searls, K., Sonnack, M., von Hippel, E. (2002) Performance assessment of the lead user idea-generation process for new product development, Management Science, 48(8), 1042-1059.

Lyles, M. A., Schwenk, C. T. (1992). Top management, strategy and organizational knowledge structures, Journal of Management Studies, 29, 155-174.

MacCrimmon, K. R., Wagner, C. (1994). Stimulating ideas through creativity software, Management Science, 40(11), 1514-1532.

Magnusson, P.R., Matthing, J., and Kristensson, P. (2003). "Managing user involvement in service innovation," Journal of Service Research, 6(2) 111-124.

Matthing, J., Kristensson, P., Gustafsson, A., and Parasuramsan, A. (2006). "Developing successful technology-based services: the issue of identifying and involving innovative users", Journal of Services Marketing 20(5) 288-97. 
Mory, E. H. (2004). Feedback research revisited. In D. H. Jonassen (Ed.), Handbook of Research on Educational Communications and Technology (pp. 745-783). Mahwah, NJ: Lawrence Erlbaum.

Nicol, D. J., \& Macfarlane-Dick, D. (2006). Formative assessment and self-regulated learning: A model and seven principles of good feedback practice. Studies in Higher Education, 31 (2), 199-218.

Osborne, A. F. (1957). Applied imagination. Charles Scribner's Sons, New York.

Paulus, P., V. Brown. (2003). Enhancing ideational creativity in groups: Lessons from research and brainstorming, P. Paulus, B. Nijstad, eds. Group Creativity: Innovation Through Collaboration, Oxford University Press, New York, 110-136.

Perry-Smith, J.E., Shalley, C.E. (2003). The Social Side of Creativity: A Static and Dynamic Social Network Perspective. Academy of Management Review, 28 (1), 89-106.

Piller, F.T., Walcher, D. (2006) Toolkits for idea competitions: a novel method to integrate users in new product development, $R \& D$ Management, 36(3), 307-318.

Plucker , J.A., Beghetto, R.A., Dow, G.T. (2004) Why isnt creativity more important to educational psychologists? Potentials, pitfalls, and future directions in creativity research, Educational Psychologist, 39(2), 83-96.

Podsakoff, P.M., MacKenzie, S., Lee, J.Y., Podsakoff, N.P. 2003. Common method Biases in behavioral research: a critical review of the literature and recommended remedies, Journal of Applied Psychology 88(5) 879-903.

Poetz, M.K., and Schreier, M. (2009) "The Value of Crowdsourcing: Can Users Really Compete with Professionals in Generating New Product Ideas?”, Druid Summer Conference, Copenhagen, Denmark. 
Submission \#16803

Prahalad, C.K., Ramaswamy, V. (2004). "Co-Creation experience: The next practice in value creation," Journal of Interactive Marketing 18(3), 5-14

Ransbotham, S., Kane, G. C. (2011). Membership Turnover and collaboration success in online communities: explaining rises and falls from grace in Wikipedia, MIS Quarterly, 35(3), 613-627.

Ransbotham, S., Kane, G., Lurie, N. H. (Forthcoming). Network Characteristics and the value of collaborative user generated content, Marketing Science, http://community.mis.temple.edu/seminars/files/2010/11/jerry1.pdf

Reid, S.E., U. de Brentani. (2004). The fuzzy front end of new product development for discontinuous innovations: A theoretical model, Journal of Product Innovation Management, 21(3) 170-184.

Roman, D. (2009) "Crowdsourcing and the Question of Expertise", Communications of the ACM, (52)12, pp. 12-12.

Sawhney, M., Verona, G., Prandelli, E. "Collaborating to create: The internet as a platform for customer engagement in product innovation, " Journal of Interactive Marketing 19(4), 2005, pp. 4-17.

Sternberg, R. J., O’ Hara, L. A. (2000). Intelligence and creativity, in R. J. Sternberg (Ed.), Handbook of Intelligence: 609-628. New York: Cambridge University Press.

Singh, J., L. Fleming. (2010). Lone inventors as sources of breakthroughs: Myth or reality? Management Science, 56(1) 41-56.

Soukhoroukova, A., Spann, M., and Skiera, B. (2012) "Sourcing, Filtering, and Evaluating New Product Ideas: An Empirical Exploration of the Performance of Idea Markets ”, Journal of Product Innovation Management, 29(1), 110-112. 
Straub, D., Boudreau, M., and Gefen, D. 2004. Validating guidelines for IS positivist research, Communications of the Association for Information Systems, 13(24) 380-427.

Taylor, A., Greve, H. R. 2006. Superman or the fantastic four? Knowledge combination and experience in innovative teams, Academy of Managmeent Journal, 49(4) 723-740.

Tschang F. T., J. Szczypula. 2006. Idea creation, constructivism, and evolution as primary characteristics in the videogame artifact design process. European Management Journal, $24(4), 270-287$.

Ulrich, K. T., S. Eppinger. (2007). Product Design and Development, $4^{\text {th }}$ ed. McGraw-Hill Higher Education, New York.

Von Hippel, E. 2005. Democratizing Innovation. MIT Press Boston, MA.

Wang, P., Ramiller, N.C. 2009. "Community learning in information technology innovation," MIS Quarterly, 33(4) 709-734.

Wasko, M., S. Faraj (2005). Why should I share? Examining social capital and knowledge contribution in electronic networks of practice, MIS Quarterly 29(1) 35-57.

Wetzels, M., Odekerken-Schröder, G., Van-Oppen, C. 2009. Using PLS path modeling for assessing hierarchical construct models: Guidelines and empirical illustration. MIS Quarterly 33(1) 177-195.

Yang, Y., P.Y. Chen, Pavlou, P. (2009). Open Innovation: An Empirical Study of Online Contests. The $30^{\text {th }}$ International Conference on Information Systems, Phoenix, Arizona. 
Submission \#16803

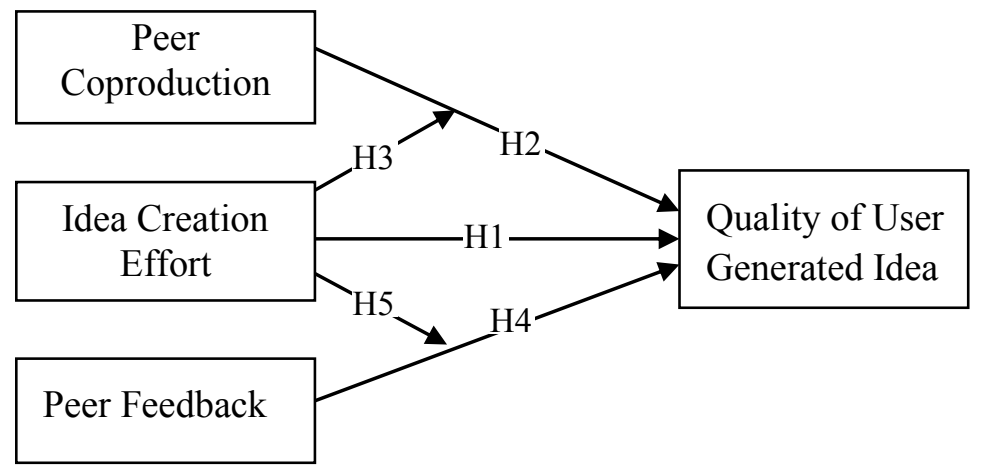

Figure 1. Proposed Research Model 


\begin{tabular}{|c|c|c|c|c|}
\hline \multicolumn{5}{|c|}{ Table 1. Construct Measurement Description } \\
\hline Variable & \multicolumn{2}{|c|}{ Measurement } & Data Source & Reference \\
\hline \multirow{3}{*}{$\begin{array}{l}\text { Quality of } \\
\text { User } \\
\text { Generated } \\
\text { Idea }\end{array}$} & Novelty & The idea is novel & \multirow{3}{*}{ Expert rating } & \multirow{3}{*}{$\begin{array}{l}\text { Blohm et al. } \\
\text { (2011); Dean et } \\
\text { al. (2006) }\end{array}$} \\
\hline & Relevance & $\begin{array}{l}\text { The idea has an attractive market } \\
\text { potential }\end{array}$ & & \\
\hline & Elaboration & $\begin{array}{l}\text { The idea is described accurately and } \\
\text { precisely }\end{array}$ & & \\
\hline \multirow{2}{*}{$\begin{array}{l}\text { Idea Creation } \\
\text { Effort }\end{array}$} & \multicolumn{2}{|c|}{ The number of revisions by the idea author } & Archival data & \multirow{2}{*}{$\begin{array}{l}\text { Ransbothams and } \\
\text { Kane (2011); } \\
\text { Yang et al. (2009) }\end{array}$} \\
\hline & \multicolumn{2}{|c|}{$\begin{array}{l}\text { The length of the idea in terms of the number of } \\
\text { word of the idea }\end{array}$} & Archival data & \\
\hline \multirow{2}{*}{$\begin{array}{l}\text { Peer } \\
\text { Coproduction } \\
\end{array}$} & \multicolumn{2}{|c|}{ The number of edits by peers } & Archival data & \multirow{4}{*}{$\begin{array}{l}\text { Ransbotham et al. } \\
\text { (forthcoming) }\end{array}$} \\
\hline & \multicolumn{2}{|c|}{ The number of peers participated } & Archival data & \\
\hline Peer Feedback & \multicolumn{2}{|c|}{$\begin{array}{l}\text { The number of comments the idea received from } \\
\text { peers }\end{array}$} & Archival data & \\
\hline Idea Duration & \multicolumn{2}{|c|}{ The time elapsed after the publication of the idea } & Archival data & \\
\hline Voting & \multicolumn{2}{|c|}{ The number of votes that the idea receives } & Archival data & \multirow{2}{*}{$\begin{array}{l}\text { Ransbothams and } \\
\text { Kane (2011) }\end{array}$} \\
\hline $\begin{array}{l}\text { Creator's } \\
\text { Experience }\end{array}$ & \multicolumn{2}{|c|}{$\begin{array}{l}\text { The number of ideas that the idea author has } \\
\text { participated in coproduction or creation }\end{array}$} & Archival data & \\
\hline
\end{tabular}

\begin{tabular}{|l|c|}
\hline \multicolumn{2}{|c|}{ Table 2. CA, CR, and AVE } \\
\hline Cronbach's Alpha (CA) & Peer Coproduction \\
\hline Composite Reliability (CR) & 0.85 \\
\hline Average Variance Extracted (AVE) & 0.93 \\
\hline
\end{tabular}

\begin{tabular}{|l|c|}
\hline Table 3. ICC-coefficients for Dimensions of Quality of User Generated Idea \\
\hline Dimension & ICC-Coefficient \\
\hline Novelty & 0.63 \\
\hline Relevance & 0.53 \\
\hline Elaboration & 0.61 \\
\hline
\end{tabular}

\begin{tabular}{|l|l|c|c|}
\hline \multicolumn{4}{|c|}{ Table 4. Weights for Formative Constructs } \\
\hline & & Weights & T-values \\
\hline \multirow{2}{*}{ Idea Creation Effort } & Revisions by Idea Author & $\mathbf{0 . 3 4}$ & $\mathbf{2 . 4 8}$ \\
\cline { 2 - 4 } & Idea Length & $\mathbf{0 . 8 7}$ & $\mathbf{1 1 . 5 3}$ \\
\hline \multirow{2}{*}{$\begin{array}{l}\text { Quality of User Generated } \\
\text { Idea }\end{array}$} & Novelty & 0.14 & 0.80 \\
\cline { 2 - 4 } & Relevance & -0.13 & 0.36 \\
\cline { 2 - 4 } & Elaboration & $\mathbf{0 . 9 7}$ & $\mathbf{4 . 7 4}$ \\
\hline$* \mathrm{p}<0.05 ; * * \mathrm{p}<0.01 ; * * * \mathrm{p}<0.001$ & & & \\
\hline
\end{tabular}




\begin{tabular}{|c|c|c|c|c|c|c|c|c|c|c|c|}
\hline \multicolumn{12}{|c|}{ Table 5. Correlation Table } \\
\hline & Mean & SD & $\begin{array}{l}\text { Peer Co- } \\
\text { production }\end{array}$ & $\begin{array}{l}\text { Idea } \\
\text { Creation } \\
\text { Effort }\end{array}$ & $\begin{array}{l}\text { Quality of } \\
\text { User } \\
\text { Generated } \\
\text { Idea }\end{array}$ & $\begin{array}{l}\text { Peer } \\
\text { Feedback }\end{array}$ & $\begin{array}{l}\text { Idea } \\
\text { Duration }\end{array}$ & $\begin{array}{l}\text { Creators' } \\
\text { Experience }\end{array}$ & \begin{tabular}{|l|} 
\\
Voting \\
\end{tabular} & $\begin{array}{l}\text { Idea Creation } \\
\text { Effort * Peer } \\
\text { Co-production }\end{array}$ & $\begin{array}{l}\text { Idea Creation } \\
\text { Effort * Peer } \\
\text { feedback }\end{array}$ \\
\hline $\begin{array}{l}\text { Peer Co- } \\
\text { production }\end{array}$ & 1.23 & 1.11 & 1.00 & & & & & & & & \\
\hline $\begin{array}{l}\text { Idea Creation } \\
\text { Effort }\end{array}$ & -* & -* & 0.18 & 1.00 & & & & & & & \\
\hline $\begin{array}{l}\text { Quality of User } \\
\text { Generated Idea }\end{array}$ & $-*$ & $-*$ & 0.15 & 0.54 & 1.00 & & & & & & \\
\hline Peer Feedback & 1.55 & 2.01 & 0.10 & 0.07 & 0.29 & 1.00 & & & & & \\
\hline Idea Duration & 21.10 & 6.44 & 0.11 & 0.13 & -0.06 & -0.34 & 1.00 & & & & \\
\hline $\begin{array}{l}\text { Creators' } \\
\text { Experience }\end{array}$ & 8.57 & 7.98 & -0.07 & 0.10 & 0.12 & 0.29 & -0.40 & 1.00 & & & \\
\hline Voting & 3.41 & 2.76 & 0.08 & 0.17 & 0.19 & 0.51 & -0.26 & 0.29 & 1.00 & & \\
\hline $\begin{array}{l}\text { Idea Creation } \\
\text { Effort * Peer } \\
\text { Co-production }\end{array}$ & $-*$ & $-*$ & -0.47 & -0.25 & -0.26 & -0.06 & -0.27 & 0.09 & -0.02 & 1.00 & \\
\hline $\begin{array}{l}\text { Idea Creation } \\
\text { Effort * Peer } \\
\text { feedback }\end{array}$ & $-*$ & $-*$ & 0.27 & 0.25 & 0.29 & 0.17 & -0.06 & 0.05 & 0.002 & 0.27 & 1.00 \\
\hline
\end{tabular}


Submission \#16803

\begin{tabular}{|l|c|c|c|}
\hline \multicolumn{4}{|c|}{ Table 6. Results of Hypotheses Testing } \\
\hline & Controls & Main Effects & Main and Interaction Effects \\
\hline Voting & $0.22 *$ & -0.03 & -0.02 \\
\hline Idea Duration & -0.11 & -0.03 & 0.02 \\
\hline Creator's Experience & -0.08 & 0.01 & 0.02 \\
\hline Peer Co-production & & 0.02 & 0.10 \\
\hline Idea Creation Effort & & $0.52 * * *$ & $0.50 * * *$ \\
\hline Peer Feedback & & $0.26 *$ & $0.24 *$ \\
\hline Peer Co-production * Idea Creation Effort & & & $-0.19 *$ \\
\hline Idea Creation Effort* Peer Feedback & & & -0.08 \\
\hline $\mathrm{R}^{2}$ & 0.07 & 0.34 & 0.37 \\
\hline Observations & & & 86 \\
\hline$* \mathrm{p}<0.05 ; * \mathrm{p}<0.01 ; * * \mathrm{p}<0.001$ & & \\
\hline
\end{tabular}

